In this presentation, the author argues that aligning learning with community contexts and processes is a way if identifying what we know, where the knowledge came from and how this knowledge is connected to successful institutional education. Moreover, viable teaching-learning, reciprocal relationships between formal institutions and community spaces can encourage educational activism. Specific community-based pedagogical components, that are not limited to art education, will be suggested as a means of connecting teachers, community members and students through educational practice.

Key-words: educational activism, community-based art education and community act. 


\section{Components of the community act as sources of pedagogy}

Vesta A. H.

DANIEL

Nesta apresentação, a autora sustenta que juntar aprendizagem aos contextos e processos de comunidade é um modo de identificar o que sabemos, de onde o conhecimento vem e como este conhecimento é conectado com uma educação institucional bem-sucedida. Portanto, viabilizar um ensino-aprendizagem com relações recíprocas entre instituições formais e espaços comunitários pode encorajar um ativismo educacional. Específicos componentes da pedagogia baseada na comunidade, que não são limitados à arte-educação, serão sugeridos como modo de conectar professores, membros da comunidade e estudantes através da prática educativa. Palavras-chave: ativismo educacional, arte-educação, ação comunitária. 
My work in higher education includes preparing students in a midwestern university in the United States to become art educators. I encourage pre-service students and in-service teachers toward a transformative conception of education. My goals include experiencing community-based art education and its potential for identifying correlations across disparate groups and connecting with the community as a source of pedagogy. I define community as a collection of people who are unified by place/ locality (or not), similar circumstances and/or history, shared interests and/or spiritual linkages.

Aligning learning with community contexts is a way of identifying what people know, where their knowledge came from and how it is connected to successful institutional education. Sources of knowledge and ways of knowing cannot be limited to a canon ordained by the Euro-male, middle class presumption of superior knowledge and interpretation of thought. Rather, the border-dwellers, members of diverse communities, civic and cultural activists and advocates are likely to be dependable sources of knowledge relevant to educational practice informed by community behaviors. The honoring of community-based approaches to the identification and use of knowledge is an aspect of community-based pedagogy. It can assist education in becoming more connected to both teachers and students. It can also transform society by providing an approach to the ideal of equity.

\section{Place and Place-Conscious Education}

Part of what informs my thinking about the significance of community to education is theories of place and placeconscious education. One of the arguments of these theories is that locations/places have pedagogical importance because they are the larger contexts of living in which education plays a part (GRUENEWALD, 2003; HOOKS, 1994; HOVEY, 2004). Gruenewald (2003) challenges educators and administrators to connect place-based experience with academic accountability. He posits that: 
If places are to matter to schooling, then accountability and purpose must be conceived in a way that appreciates the value of places as a primary context for experience, as a pathway to authentic democratic participation, and as the living legacy of human engagement with the world. (2003, p. 645)

In addition to being a source of knowledge that informs pedagogy, the community can function as a site/place of resistance by providing subject matter and behaviors that invite critical dialogue. That is, status quo educational practices that depend on the unidirectional interaction between teacher and student can be reshaped into a multidirectional, multi-voiced, multilayered instructive collaboration. Education that honors the societal microcosm of community-based education prepares students for the macrocosm of the world community.

The participation of teachers and students in the bidirectional experience of each other, as people from different spaces, is another aspect of community-based pedagogy. Teachers from majority culture (which might not translate into numerical majority) will need to participate in this experience themselves before they can become trusted and effective in culturally, racially, ethnically diverse contexts. In many instances they will need to learn to become deeply interested in their students' personal contexts in order to build and deliver engaging curricular content.

Some educators, in an attempt to accommodate for curricular content that is culturally or racially impoverished, misleading or just wrong, have provided community-based experiences for students who are preparing to be teachers. Teachers may rationalize that students who are merely present in new/ unfamiliar community contexts/places such as recreation centers, cultural centers, artists' workshops, community centers and after-school programs will be prepared to teach in those contexts. However, unless the teacher and students become connected to the ethos, practices, goals, problem-solving strategies, experiences and narratives that characterize that community, the community-based experience is reduced to an exercise without purpose. 


\section{The Community as a Source of Prior Knowledge}

Student and teacher experiences are sources of prior knowledge that comes from a community connection of some kind, whether that connection was rich, wholly engaging, supportive and nurturing or distant and regrettable. Use of prior knowledge that might come from the home or community is related to the process of education. Shapiro (2004), in a study of what students learn from reading a text, found that "the content of prior knowledge can alter the degree to which readers extract information from a text" (p. 162), and that while "accurate prior knowledge can aid learners in extracting information from a text, inaccurate prior knowledge can actually interfere with learning." (p. 163). Lipson's studies in 1982 and 1983 (as cited in SHAPIRO, 2004) caution that it is more difficult to change incorrect prior knowledge in the learning process than it is to learn unfamiliar information. Teachers and community members who struggle to correct misconceptions based on biases, stereotypes, unfounded fears of unfamiliar people, cultures and communities are attempting to correct inaccurate prior knowledge. Shapiro (2004) suggests that teachers who can determine what students already know, what knowledge they bring with them to school can better determine what they are learning in school. Moreover, as Freire (1972) posits, teachers must become familiar with the lives and realities of their students. They must honor the knowledge that they bring from their experiential contexts as educationally relevant, engaging, emancipatory and empowering for both students and teachers.

The knowledge that I can identify as a consequence of my involvement with community acts helps me to identify some of the goals that the community groups seem to share, such as: - developing self-sufficiency through commercial initiatives;

- creating and exhibiting political and cultural self-determination through their own efforts;

- initiating and participating in environmental improvement;

- exploring and sharing personal histories, philosophies and cosmologies as a significant aspect of a collective history;

- using art, personal and community aesthetics and art education as tools for social transformation; 
- publicly and privately celebrating, valuing and observing beliefs and significant personal and community practices;

- giving voice to the voiceless.

As I became more familiar with these goals I began to understand that they are created from and informed by past and ongoing lived experiences, just as the goals for formal education should be. Moreover, it seems that in order for educators to address goals that are meaningful and valuable for both students and teachers, the characteristics of a community act should be clear to them and to the students. By identifying and participating in positive, creative community acts educational pedagogy can be enlightened and uplifted and communitybased epistemology can be recognized and used profitably as curricular content.

\section{Characteristics of the community-act}

1. Process orientation. This aspect of the community-act refers to the nature of the approach to doing the act. A feature of the community-act process is that it might not appear to have clear rules or guidelines. For example, the following "process objectives" might never be spoken or considered important because to do so might hamper the fluidity of the process:

a. objectives of the process must be clearly stated at the beginning of each procedure;

b. each part of this discussion should take only 15 minutes to complete.

Nevertheless, the process probably has a system of operation and it moves toward a goal which is the production of something such as a material product or an idea to be explored and acted upon, perhaps in the form of a goal. The process is likely to involve a series of actions, which might or might not be formalized. The process is the mother of the product. My students have observed that it is sometimes difficult for them to lessen their concern about a product (e.g., the creation of a curriculum or a student art exhibition). However, I have noticed that people who educate from a community base recog- 
nize, and typically will not abandon, the importance of processes in identifying and reaching goals of concern to a particular community.

2. Dynamic and evolutionary. Because communities are typically internally diverse, community members bring various styles of participation, communication, and timing. In that respect the community is like a classroom of diverse learners. However, unlike many classroom situations where the teacher can (fortunately or unfortunately) often direct the teacher-student interaction, the community-act can be propelled by dynamic "fits and starts" of energetic and forceful motion toward a goal. To the frustration of some, this motion can cause many changes in orientation and structure to occur en route to a goal. Concomitantly, the evolutionary nature of a communityact can cause achievement to occur more gradually through an unfolding process or a process of disclosure that leads to a different level of awareness among community members. In other words, as the process evolves so does the thinking and understanding of the community members. If a person were to stand outside of this behavior, as an informed observer, they would probably be able to note specific disclosures and instances of awareness among participants in the process.

3. Non-linearity (probably). A linear process is defined as straight and narrow with one element proceeding in an orderly fashion and related to another. Like line, it may be a path or track lacking breadth and thickness. North American learners are often encouraged to think linearly and to avoid distractions that divert them from their straight and narrow path. However, there are communities of learners who, because of cultural patterns, learning styles, educational environments and/ or creative characteristics, use a multidimensional, augmented path for identifying and reaching their goals. For example, in a community discussion devoted to creating a plan for constructing a community playground it may be necessary to:

- reconstruct, through discussion, historical accounts of events that are important to individuals and groups in that community space; 
- talk about experiences that friends and relatives have had that seem only remotely related to the issue at hand, but in fact provide "life lessons" from the past that enable our decisions for the present and the future;

- display and appreciate affirmations and/or photographs of loved ones and heroes for the purpose of establishing a supportive environment through homage to one's ancestors or predecessors, and;

- establish why each person is present and participating in this discussion.

This process is non-linear in the sense that any of these four behaviors can be added to the discussion in any order, concurrently and/or at any time. This is not confusion. The participants understand that this enhanced path is significant to reaching their goal because it is experience-based and therefore connected to their lives. Participation in such a multilayered path demonstrates respect for the significance of collective experiences that generate important information and reflect knowledge that has been earned through experience.

4. Functions as a formative matrix nurtured by the interaction of history, philosophy, tradition, context and emotion. In this postmodern, constructivist period of our history we are cognizant of the interaction of variables in our lives that assist or prohibit the construction of personal meaning, knowledge and understanding. Certainly, the concept of a community-act as an educational method predates the theories of postmodernism and constructivism and it has historically been evident in communities around the world. The community most familiar to me (in addition to the American university community) is urban and African-centered. This inter-generational, trans-gendered grouping includes many sectors of the African Diaspora (e.g., black people primarily, but not exclusively, in Africa, North and South America, Europe and the Caribbean) as well as people who are not African-descended. Community membership also crosses economic and educational territories. It is characterized by, but not limited to geographic proximity. A sense of shared historical experience and philosophical un- 
derpinning provides both consonance and dissonance among the community members. However, it is understood, for example, that our traditional, contextual and emotional relationship to our children works in concert with our varied social, aesthetic and educational goals. We are aware that our decisions cannot be reasonably separated from our contextual realities and we are also aware that proactive community acts are a fundamental component of child and adult education. I sense that the schools know this too but that they are unsure of how to act on it.

5. A form of spirit work. A tour of your local bookstore is likely to reveal a collection of readings devoted to the care and feeding of the spirit. Spirit might be considered to be the unseen, intangible force that animates living beings, probably with or without our knowledge or approval. The Brazilian artist, Regina Vater, in discussing the influence of African heritage in Brazil provides an exploration of the concept of spirit:

The vibration of ancient wisdoms of Africa still reverberate in many things in Brazil: in our sensorial spirituality, in our magical connection to life, in the endurance and patience under the most adverse conditions, in our stubborn hope for "better days."

In the spontaneous connection to joy, in the strong sense of sweetness and generosity of love, in the freedom and inventiveness of the body, in the admirable musical Brazilian ear, and in the flexibility and adaptability in the face of the new (1997, p. 72).

Note that I am not referring to religion. Rather, spirit work refers here to the activity that animates you, affirms you, inspires you and your community, and ultimately satisfies you. Spirit work is related to Chandler's (1997) suggestion that "artistic genius is not a matter of gender or race unless those identities are linked with spiritual agency - the power to make good things happen, even in bad times" (p. 81).

Teachers who are aware that spirit work may be an important part of the experiences of the diverse North American cultures will be more facile at working with varied students. For example, Ani (1994, p. 203) offers that for some students, who may be informed by certain African belief systems, the 
creation of art should always be communal and spiritual, if it is to be moral:

In the African view of the human, the emotional-spiritual and the rational-material are inextricably bound together, and if anything, it is a human being's spirituality that defines her as human, providing the context within which she is able to create art as well as technology... The emotional identification with, and participation in, the art form by the person and the community are primary values that help to determine its shape... While [European] artists may still attempt to evoke certain isolated emotional responses from their audiences, these responses theoretically have very little "cultural" or "moral" significance...

In a community setting, spirit work might necessarily include a sense of action for the collective good. The reason that you do this work may be non-discursive, much the way our experience with art may be difficult to verbalize. Conversely, participants in the community might be explicit in the nature of the spirit work to be done as in the case of the creation of the Kwanzaa Playground in Columbus, Ohio. The seven community artists, whose work is permanently installed in the playground, had been exposed to aspects of African-centered thought and they identified with it in varying degrees. Much of their artwork reflected their internalization of qualities that might be defined as spiritual. Delpit's (2003) discussion of the work of Asa Hilliard in 1997 (as cited in DELPIT, 2003) about African traditional/contemporary education helps to bring focus to the significant relationship between spirit and education. Delpit (2003) notes that the education of the mind and body are accomplished together and that the "divine temple" (p. 16) of the body houses the spirit. Bodily and spiritual education are thus linked together. "Therefore, in the African tradition, it is the role of the teacher to appeal to the intellect, the humanity, and the spirituality in their students" (DELPIT, 2003, p. 16). The Kwanzaa Playground artists endeavored to address the intellect, humanity and spirituality of those entering the playground by doing the following spirit work:

- making visible through their art, the effect of African cosmologies on their art; 
- providing examples of African inspired aesthetics and symbols that evoke positive life-lessons such as those found in adinkra symbols;

- making invisible cultures visible to all communities;

- illustrating that children are valued; they are part of a collective, a family and a community;

- illustrating the positive relationship between self-determination and community action.

6) Valorized by narrative. An aspect of youth culture that is evolving into an international phenomenon is a form of performance art called spoken word. It is poetic, sometimes freestyle and unscripted, and sometimes it is laboriously crafted, emotive-narrative. This type of story telling is seen and heard in public spaces, clubs, theaters, television, radio, community spaces and schools. Humorous, forceful and poignant language is used to create what might also be considered counter-narratives (HOOKS, 2003) which are spoken resistance to the master-narratives of hegemony, supremacy, power and privilege. In Creswell's (1994) description of research methodologies, he characterizes qualitative narrative as a research procedure that emerges from data analysis. It is a tale that is either realist, confessional or impressionist. These descriptors are shared with spoken word as narrative. The data being analyzed is one's life-based experience and the nature of the narrative is either realistic, confessional or impressionistic or some combination of these.

A narrative is the telling of a story. It requires an understandable context, necessary background, descriptive details and chronological markers (LUNSFORD \& CONNORS, 1995). Religious narratives (e.g., biblical, Koranic) and historical narratives (e.g., slave, military) are examples of this type of story telling. As an artist-educator and arts advocate, Ana Mae Barbosa effectively explores the difficulties of Brazilian women artists through her own narratives (BARBOSA, 1997). The African American critical theorist bell hooks uses her narratives to illustrate the application of race-based ideologies to education (HOOKS, 1994, 2003). Many students have stories to tell 
that can help to make a connection between them and their teachers and can ultimately inspire and inform the curriculum and classroom ecology.

If a teacher were to consider my narrative, for example, it would include the following elements, among others. Philosophically, culturally and ethnically I identify myself as an African-American woman who is a product of the Civil Rights Movement in the United States. In an obvious way my destiny was influenced by Brown v. Board of Education of Topeka, Kansas in 1954, which eradicated legalized segregation in public schools and the Civil Rights Act of 1964, which was intended to end legalized segregation of black and white people in the southern part of the United States and in public places throughout the country. However, the lives and destinies of my parents, and their fore parents, dating back to the fifteenth century, were profoundly influenced by the atrocities of the trans-Atlantic slave trade. Of the 15 million Africans forcefully transported from Africa by Europeans and North Americans the largest number were sent to South America, followed by those sent to North America and islands of the Caribbean. I recognize that from that time until now African-descended people in the world Diaspora have been confronted with the challenge, rather than the right and expectation to self-name and to fight for and maintain a significant historical and cultural presence on many unreceptive fronts.

My educational experiences (as both student and teacher) range from majority African American schools to majority white schools. In each of the white school contexts I was fully aware that people who looked like me were omitted from historical accounts focusing on inventive, creative and monumental contributions to the development of the United States and the world. My educational experiences cover several decades and might suggest contemporary irrelevance. However, one month ago a graduate student told me that she intended to conduct research on the omission and/or mismanagement of African and African American art curricular content and the lack of teacher preparation, expertise and/or willingness to include this material in their curriculums. Two months ago, a 
group of white students told me that they were appalled to find that their student peers, who are also white, were uninterested in discussing the significance of race (e.g., racialized imagery as an aspect of visual culture) especially if they were not teaching black students.

It would be important for my teacher to know that the practice of self-naming is a component of my narrative as well as an aspect of self-determination. It means that individuals can choose their identity rather than having it assigned to them. In the United States, public and private identity is typically based on bipolarities such as black/white, male/female, rich/poor, heterosexual/homosexual and educated/uneducated. Teachers might need to reflect on whether their personal philosophies, personal narratives, the ecologies of their classrooms and their teaching practices include resistance to these polarities as determinants of educational access and social equity.

If my teacher studied my narrative in relation to my community she could teach and learn with full consciousness of the following three concepts: 1 . race, and the heinous socialcultural consequences of racism, are significant phenomena that affect ones experiential reality as a North American or as a migrant to the North American context; 2. racial designation in the United States affects the extent to which quality education will be available and it influences curricular content; 3.teachers who are uninterested in the narratives of their students, including the impact of race, may find it difficult to use curricular content in an engaging and meaningful way (DANIEL, 2003).

\section{Conclusion}

Educators may wish to be involved in art education as a community-act because the process: gives purpose to an often directionless approach to educational involvement in community-based art experiences; provides a perspective on pedagogy that is based on what the community knows; teaches formal educators about the process, philosophy and value of com- 
munity-based art and research; provides insight into components of knowledge that is evolutionary, situated, contextual, and process - and product-oriented, and; calls for educators and researchers to explore their tendency to be exploitative regarding "the community". Hooks (1994), who might sum up these components as "engaged pedagogy", would add that this approach to partnering the educational goals of schools and communities is "an expression of political activism" (HOOKS, 1994, p. 202-203).

Educator familiarity with characteristics of the community act can support ways of teaching and learning by transferring knowledge through action from the micro-community to the macro-community (or from within the community to beyond the community). The engagement of teachers with the narratives of students and their communities can energize the curriculum and might, as Delpit (2003, p. 15) suggests save teachers from "burnout by helping make instruction powerful, engaging, and effective".

I encourage teachers to engage with communities as sources of knowledge and pedagogy, and to participate in an interactive teaching and learning experience with their students. Such an engagement can encourage critical thinking as one becomes familiar with voices and ways of knowing from communities at the borders of mainstream society. The welcome consequence might be the movement of knowledge from one community to another resulting in education that is more connected to life. 


\section{Note}

1- Presented at the XV CONFAEB-Brazilian Federation of Art Educators Congress, November 1214, Rio de Janeiro, Brazil. 


\section{References}

ANI, M. (1994). Yurugu. An African-centered Critique of European Cultural Thought and Behavior. Trenton: Africa World Press, Inc.

BARBOSA, A.M. (1997). Art in Brazil: Several minorities. In P. Farris-Dufrene, Voices of color. Art and society in the Americas. New Jersey: Humanities.

CHANDLER, R. The new movement of the center: A theoretical model for future analysis in art worlds. In P. Dufrene (Ed.) Voices of Color: Art and society in the Americas. New Jersey: Humanities Press, 1997.

CRESWELL, J.W. (1994). Research Design. Qualitative \& Quantitative Approaches. Thousand Oaks: Sage.

DANIEL, V.A.H. (2003). The Kwanzaa playground narrative: an anchor for integrated curriculum in art education. The International Journal of Arts Education, 1(2), 6-15.

Art education as a community act: teaching and Learning through the community. Proceedings of the International Symposium in Art Education, Taipei, Taiwan, R.O.C, 2001, p. 1-13.

DELPIT, L. (2003). Educators as "seed people" growing a new future. Educational Researcher, 7(32), 14-21.

FREIRE, P. (1972). Pedagogy of the Oppressed, Harmondsworth: Penguin.

GRUENEWALD, D. (2003). Foundations of place: A multidisciplinary framework for place-conscious education. American Educational Research Journal, 40(3), 619-654.

HOOKS, B. (1994). Teaching to Transgress. Education as the practice of freedom. New York: Routledge.

HOOKS, B. (2003). Teaching community. A pedagogy of hope. New York; Routledge.

HOVEY, K. (2004). Spatial, social theory applied to the Kwanzaa Playground: Implications and applications for art educators. Unpublished doctoral dissertation, The Ohio State University, Columbus.

LUNSFORD, A. \& CONNORS, R. (1995). The New St. Martin's Handbook. Boston: Bedford/St. Martin's.

SHAPIRO, A. (2004). Effects of including prior knowledge as a subject variable. American Educational Research Journal, 41(1), 159-189.

VATER, R. (1997). The continent of Ashe. In P. Farris Dufrene (Ed.), Voices of Color. Art and society in the Americas. New Jersey: Humanities.

Vesta Daniel

Department of Art Education, The Ohio State University Columbus, Ohio, USA. 